\title{
Antibodies and Tyrosine Kinase Inhibitors in Breast Cancer Therapies
}

\author{
J. Barth ${ }^{\mathrm{a}}$ Christian Jackisch $^{\mathrm{b}} \quad$ Michael Untch $^{\mathrm{c}}$ \\ a StiL (Study Group of Indolent Lymphomas) Central Office, Med Klin IV, Giessen, Justus-Liebig-University, \\ ${ }^{b}$ Department of Obstetrics and Gynecology and Breast Center, Klinikum Offenbach GmbH, Offenbach, \\ ${ }^{c}$ Department of Obstetrics and Gynecology and Breast Center, HELIOS-Klinikum Berlin-Buch, Akademisches Lehrkrankenhaus der \\ Universitätsmedizin Charité, Berlin, Germany
}

\section{Key Words}

Molecular mechanisms of pharmacological action . Antibodies - Receptor protein tyrosine kinases

\section{Summary}

In recent years, new classes of molecules have been established as opportunities for the treatment of breast cancer. The approval of trastuzumab, the antibody against Her2/neu, in the late 1990s was followed by the approval of the antiangiogenic antibody bevacizumab in 2007. Progress in the understanding of the molecular mechanisms of carcinogenesis and tumour growth led to the development of new molecules, mostly kinase inhibitors. A few of these new molecues gained approval in several countries; clinical trials aiming at further approvals are ongoing. This short review covers the actual state-of-the-art and possible future developments in the targeted therapy of breast cancer.

\section{Tumour-Induced Angiogenesis Is a Target of Breast Cancer Therapeutics}

A tumour sized bigger than a few cubic millimetres is not sufficiently nourished by diffusion from the surrounding tissue. Hypoxic areas appear especially inside the tumour. This hypoxic microenvironment induces hypoxia-inducible factor (HIF)-1 and -2. Activation of hypoxia-responsive elements within the nucleus induces the transcription of several genes coding for proteins regulating energy metabolism, erythropoesis, cell growth, cell survival, vascular remodelling and vasomotoric reactions including angiogenesis and growth factors. Normally, up- and down-regulation of angiogenesis is in

\section{Schlüsselwörter}

Molekulare Grundlagen pharmakologischer Wirkung • Antikörper · Rezeptor-Protein-Tyrosinkinasen

\section{Zusammenfassung}

In den vergangenen Jahren haben neue Substanzklassen Einzug in die Therapie des Mammakarzinoms gehalten. Beginnend mit der Zulassung des Anti-HER2/neu Antikörpers Trastuzumab Ende der 1990er-Jahre folgte die Zulassung des antiangiogenen Antikörpers Bevacizumab im Jahre 2007. Fortschritte im Verständnis molekularer Grundlagen der Karzinogenese und des Tumorwachstums bescheren uns weitere Substanzen, vornehmlich aus der Klasse der Kinaseinhibitoren. Die ersten neuen Substanzen sind in verschiedenen Ländern zugelassen, für viele weitere laufen derzeit weitreichende Zulassungsstudien. Dieser Beitrag gibt eine kurze Übersicht zu Status quo und möglichen Entwicklungen in der zielgerichteten Therapie des Mammakarzinoms.

a stable equilibrium; in a hypoxic situation, however, angiogenesis is augmented. For better supply with nutrients, the tumour directs blood vessel growth towards itself. Development of blood- and lymphangiosis depends on members of the vascular endothelial growth factor (VEGF) protein family and their receptors. VEGF-A, VEGF-B, VEGF-C, VEGF-D, VEGF-E and placenta growth factor (PlGF) are ligands of the VEGF receptors. VEGF receptors are members of the receptor tyrosine kinase family, comprising VEGFR-1 (also Flt-1), VEGFR-2 (= Flk in mice, KDR in human) and VEGFR-3 (also Flt-4). These receptors consist of an extracellular domain showing homology to immunoglobulins and an intracellular tyrosine kinase domain. Other receptors recognising

\section{KARGER}

Fax +497614520714

Information@Karger.de

www.karger.com (c) 2009 S. Karger GmbH, Freiburg

Accessible online at:

www.karger.com/brc 
VEGFs are the non-tyrosine kinase receptors of neuropilin (NRP)-1 and -2. Binding of a ligand induces receptor dimerisation and activation, followed by signal transduction with a direct proangiogenic effect. VEGF-A is the most effective and direct proangiogenic factor [1-4].

Antiangiogenic therapy can have different targets. Slightly antiangiogenic effects of clinically used cytostatics or prolonged low-dose application of these agents (metronomic therapy) are not covered in this review. Molecules influencing malignant angiogenesis are called vascular targeting agents (VTA). Small molecules (mostly tyrosine kinase antagonists) inactivate receptors on the cytoplasmatic site and modify the signal transduction triggered from the receptor. Antagonistic antibodies might block the receptor completely (not achieved yet). Another option, carried out by the first approved antiangiogenic molecule, is to intercept agonistic ligands before they can reach the receptor. Bevacizumab is a monoclonal antibody against VEGF-A and its isoforms. The biological activity of VEGF-A is neutralised; no VEGF receptor activation occurs. In consequence, reduced tumour vascularisation inhibits tumour growth.

\section{Breast Cancer and Antiangiogenesis}

A positive correlation between angiogenesis and clinical pathology has been shown $[5,6]$. This is the rationale to use bevacizumab for the treatment of breast cancer. The monoclonal antibody is approved in combination with paclitaxel for firstline therapy of metastatic disease [7].

Antiangiogenic therapy influences the primary therapy of the tumour, inhibits occurrence of metastases and has an impact on minimal residual disease (MRD; i.e. micrometastases). Vast tumour masses are hardly reduced by antiangiogenic therapy alone. This warrants the exploration of antiangiogenic therapy in the adjuvant setting. A pilot Eastern Cooperative Oncology Group (ECOG) safety study investigated the combination of bevacizumab with conventional cytotoxic chemotherapy in the treatment of breast cancer with positive lymph nodes after surgery [8]. Other antibodies and derivates and small molecules, either targeting VEGF receptor ligands or inhibiting receptor activation-dependent downstream signalling are under investigation. Aflibercept (syn.: VEGF-Trap) is a fusion protein using key domains of the VEGF receptor family. It is a completely human decoy receptor, highly specific for VEGF-A, and binds all VEGF-A isoforms with 100-fold higher affinity compared to bevacizumab. Besides, it also binds to VEGF-C and -D and PIGF $[9,10]$. Among orally applicable small molecules, only sunitinib is approved as a purely antiangiogenic agent (inhibited kinases: VEGFR, PDGFR, FLT-3, c-Kit; approval: imatinib resistant, c-Kit-positive gastrointestinal tumours of stroma, interferon (IFN)- $\alpha$ - or interleukin (IL)-2-refractory renal cell carcinoma). Sorafenib is another molecule influencing angiogenesis by inhibition of the tyrosin kinases c-Kit, FLT-3, VEGFR-2 and -3. Initially, only the Ser/ Thr kinases RAF-B and -C were supposed to be the targets of inhibition (approval: liver and renal cell carcinoma, clinical trials for breast cancer [11, 12]). Vandetanib (ZD 6474) is a dual inhibitor of VEGFR-2, RET, and epidermal growth factor receptor (EGFR), the main target being VEGFR-2. The antiangiogenic effect predominates, because the affinity to EGFR is 12.5 times lower than to VEGFR ( $500 \mathrm{nM}$ for EGFR vs. $40 \mathrm{nM}$ for VEGFR). Another antiangiogenic molecule under clinical investigation is vatalanib (PTK787/ZK222584).

\section{Limits of Antiangiogenesis}

Conventional cytotoxic chemotherapy is limited by organ toxicity. In contrast, antiangiogenic therapy is self-limiting. Tumour vessels are irregular, branching chaotically, including 'dead-end' vessels, and vary in width, show partly defective basal layers and, by means of 'endothelial windows', are more or less permeable. They are abnormal in structure and function. As a consequence, blood flow in the tumour varies, causing hypoxic and 'acidic' areas. This abnormal blood supply hinders an effective perfusion of (classical) cytostatics and thereby an optimal response. During antiangiogenic therapy, a phase of normalisation of tumour vessel structure is possible. In this phase, cytostatics are delivered to the tumour most effectively. With continued antiangiogenic therapy in effective dosage, blood supply for the tumour becomes inadequate and perfusion with cytostatics is reduced. Insufficient blood supply again generates relatively large hypoxic areas lacking sufficient delivery of nutrients. This means stress for the tumour and can be understood as selection pressure. The tumour might in return up-regulate expression and transcription (via HIF-1 und HIF-2) of autocrine synthesis of growth factors including proangiogenic mediators, and thereby overdrive antiangiogenic therapy (compensatory response). The tumour is resistant [13]. Optimal dosage and optimal duration of therapy with antiangiogenic molecules is critical. Several mechanisms of resistance are discussed. Vessel endothelium cells may be as heterogeneous as the surrounding tumour and exhibit sporadic mutations. In endothelial cells of non-Hodgkin-lymphomas, the same chromosomal abnormalities as in the tumour were detectable. In breast cancer, the polymorphism in angiogenic genes seems to play a functional role. Invasive tumours express multiple angiogenic factors. This heterogeneity might lead to resistance in several cells. If the biologically active molecules do not reach the locus of neovascularisation in effective dosage, resistance occurs as well (reviewed in [14]).

Finally, antiangiogenic therapy with bevacizumab does not match the criteria for targeted therapy in the narrow sense of the definition. A targeted therapy should selectively influence biological processes supporting the tumour. These processes should ideally be associated with malignancy (e.g. fusion pro- 
tein BCR-Abl in Philadelphia chromosome-positive chronic myeloid leukaemia is a molecular driver of the disease). To date, there is no type of cancer with an existing measurable parameter that could be measured in correlation with response to antiangiogenic therapy. Antiangiogenic therapy is targeted in a functional sense only. In a more narrow sense, this would be the inhibition of neoangiogenesis of vessels supporting exclusively the tumour [15].

\section{ErbB2 Receptor Signalling Is a Target of Breast Cancer Therapeutics}

The family of cell membrane-bound EGFRs comprises four related but functionally different homologues, EGFR-1 to EGFR-4 (syn.: HER1 to HER4 or ErbB1 to ErbB4). Binding of an extracellular ligand leads to homo- or heterodimerisation of inactive monomers. Conformational changes activate the intracellular kinase domain and then autophosphorylation occurs. This phosphorylation leads to the recruitment of adaptor molecules (e.g. Grb1, SOS), which in turn switch on downstream signalling cascades like phosphatidylinositol 3-kinase (PI3K)/Akt, JAK/STAT or Ras. In summary, the overall effects are tumour proliferation and inhibition of apoptosis (the latter mainly through PI3K/Akt). HER3 does not show any tyrosine kinase activity on its own, but is needed and used as a partner for heterodimerisation.

Within the EGFR family, HER2 is unique since its conformation is always open. Therefore, no binding of a ligand is necessary for dimerisation; HER2 is constitutionally ready for dimerisation with other ligand-bound family members. HER2 may be considered as preferred partner for dimerisation $[16,17]$. A physiological ligand for HER2 has not yet been identified. In $25-30 \%$ of all breast cancers, amplification of the HER2/neu oncogene leads to overexpression of the membrane-bound HER2 receptors. In 1987, Slamon et al. [18] showed for the first time that overexpression of HER2/ neu is correlated with fast progression and often metastatic clinical progress of the disease (survival, time-to-progression). A certain threshold of expression must be crossed to lead to malignant transformation and hetero-/oligomerisation, and HER2 seems to be mandatory for an enhanced/changed signal transduction. A receptor dimer seems to be the minimally functional unit necessary for ErbB receptor signal transduction. Spontaneous ligand-independent dimerisation is experimentally inducible with a receptor density on the cell surface of more than 100,000/cell.

ErbB2 (HER2) is the preferred partner for dimerisation with other receptors of the Erb family. Stronger binding of the ligand and/or slower dissociation from the receptor have synergistic transforming effects, above all when in co-expression with the EGFR (HER2/EGFR heterodimer). In such a combination, a low-affinity binding site is changed to a highaffinity binding site, resulting in a lower level of ligand dis- sociation, for example. HER2 bi-/heteromerisation leads to increased tyrosine kinase activity and/or constitutive tyrosine kinase activity with or without stimulating ligand (cross-phosphorylation between monomers), followed by deregulated signal transduction enhancing proliferation.

Not only the extracellular but also the intracellular domain of the receptor seems to be important for dimerisation and tetramerisation by building energetically stable structures. Quality and quantity of signal transduction seem to depend on combination partner, ligand (ligand differentiation) and phosphorylation site(s). This is a physiological mechanism of signal diversification (e.g. [19-22]).

\section{Antibodies Targeting ErbB2 in Breast Cancer}

The antibody muMAb4D5, originally murine, was humanised and is now used against HER2-overexpressing breast cancer - trastuzumab. The therapeutic molecule targets the extracellular domain of the receptor and in the late 1990s gained Food and Drug Administration (FDA) and European Medicines Agency (EMEA) approval for therapy of HER2/neu-overexpressing breast cancer. Binding of the antibody to the receptor at least reduces multiple HER2-activated signalling cascades in their intensity. Trastuzumab-mediated internalisation and decomposition of the receptor are under discussion. It could be shown that receptor density at the cell surface remains unchanged under therapy with trastuzumab, regardless of a clinical response. Trastuzumab could also disrupt interaction between HER2 and cytosolic Src kinase. Inactivation of Src leads to activation of the PI3K inhibitor PTEN (phosphatase and tensin homolog deleted on chromosome ten), a tumour suppressor gene product. Activation of PTEN phosphatase rapidly leads to Akt dephosphorylation and inhibits cell proliferation. Cells treated with trastuzumab arrest the cell cycle in G1 phase. An explanation is, inter alia, augmented release and diminished proteasomal degradation of p27 $7^{\text {kip }}$ a cyclin-dependent kinase inhibitor and cell cycle regulator and tumour suppressor. Classical mechanisms of immunological response, antibody-dependent cellular cytotoxicity (ADCC), should not be left unmentioned (reviewed in [23]).

Pertuzumab is a recombinant, humanised anti-HER2 inhibiting ligand-associated dimerisation of HER2 with other members of the receptor family. It was the first classified representative of the HER dimerisation inhibitors (HDIs) [24]. The antibody is under clinical investigation against cancers of prostate, ovaries, head and neck, and against melanomas [25, 26].

\section{Problems and Restrictions of Antibody-Based Therapies}

A basic problem of antibody therapy against solid tumours may be large tumour masses (possibly heterogeneous anti- 
gen distribution) resulting in poor biodistribution. Unspecific binding of antibody to benign tissues possibly enhances toxicity. If antigen shedding into the blood circulation occurs, the kinetics of drug delivery is no longer optimal. Antigen modulation is another reason for jeopardising antibody delivery to the tumour.

On the other hand, there are hindrances to kill tumour cells. Endogenous cytotoxic mechanisms (e.g. PTEN deficiency) might be missing or tumour cells could acquire resistance against cytotoxic mechanisms. Heterogeneous expression of antigens or subclones not expressing those antigens would impair the mechanism of action against the tumour cell. In general, missing of antigen expression or appearance of antigen-negative tumour cells probably causes resistance of the tumour against a monoclonal antibody.

Most patients responding to trastuzumab suffer from recurrent disease within 1 year [23]. A better understanding of the mechanisms of resistance against trastuzumab is necessary to find new successful combinations with other targeted therapies.

\section{Altered Receptor-Antibody Interaction}

Resistance against an antibody is possibly due to an inhibition of the interaction between therapeutical molecule and target protein. Trastuzumab resistance is associated with augmented expression of the membrane-associated glycoprotein MUC4. MUC4 sterically hinders binding of trastuzumab to the HER2 receptor by binding to the receptor and inducing its phosphorylation [27]. Due to a mutation in the her 2 gene, the extracellular domain of the HER2 receptor might be changed so that trastuzumab is not able to bind. These mutations are found in lung cancer [28]. During time the number of receptors on the surface of the cell might decrease; however, there is no immunohistochemical evidence for this in patients not showing a pathologically complete remission [29].

\section{Increased Cell Signalling}

Constitutive or enhanced Akt signal transduction is one mechanism of trastuzumab resistance [30]. Trastuzumab inhibits signal transduction starting from the HER2 receptor but not the other HER receptors. EGFR/HER3 dimers might compensate for the failure of HER2 by activation of PI3K/Akt [31]. For this reason several molecules inhibiting more than one member of the HER family are in clinical development. In studies, tumours showing up-regulated Akt signal transduction and highly phosphorylated mitogen-activated protein kinase (MAPK) responded to lapatinib but not to trastuzumab [32]. Pertuzumab and trastuzumab synergistically inhibit the survival of HER2-positive breast cancer cells [32]. PTEN down-regulation blocks trastuzumab-transmitted inhibition of proliferation [33]. In cell culture, trastuzumab increases the p27/Cdk2 ratio in the nucleus and inhibits Cdk2 activity and proliferation of HER2-positive cells. Cell cycle deregulation at least in part seems to depend on PI3K inhibition and low Akt activation [30].

\section{Insulin-Like Growth Factor Receptor Signalling}

High levels of insulin-like growth factor (IGF) inhibit radiation-induced apoptosis. In breast cancer models, trastuzumab resistance is associated with up-regulated IGF-1R. IGF-1R signal transduction possibly is a trastuzumab target [34]. Crosstalk between IGF-1R and HER2 leads to HER2 phosphorylation in trastuzumab-resistant but not in trastuzumab-sensitive cells. IGF-1R stimulation also down-regulates p27 [35].

\section{Small Molecular Tyrosine Kinase Inhibitors Inhibit ErbB Signaling}

Intracellular receptor tyrosine kinase activity of EGFR can be inhibited by small molecules (see above). Besides erlotinib and gefitinib, also lapatinib is available, inhibiting both ErbB1 and, for breast cancer clinically more important, ErbB2. Lapatinib is approved for the treatment of advanced or metastatic breast cancer in combination with capecitabine.

Trastuzumab and pertuzumab target the extracellular domain of the HER2 receptor; lapatinib, however, blocks the intracellular receptor tyrosine kinase domain, acting as ATP mimetic and inhibiting downstream signal transduction. The 4-anilinquinazolin derivative is a dual, reversible inhibitor of the receptor tyrosine kinases ErbB1 and ErbB2. It is 300-fold more selective for ErbB1/2 than for other tested kinases. In contrast to trastuzumab, lapatinib also inhibits phosphorylation of $\mathrm{p}^{95} \mathrm{HER} 2$, a truncated HER2 receptor missing the extracellular domain. Lapatinib is effective in heavily pretreated patients and also in trastuzumab-resistant metastatic or inflammatory breast cancer expressing ErbB and overexpressing ErbB2. Good results in the metastatic setting warrant clinical trials of the tyrosine kinase inhibitor lapatinib in earlier stages of the disease [36]. Metastases of the brain are common in HER2positive breast cancer and often occur under therapy with trastuzumab. The antibody trastuzumab does not cross the bloodbrain barrier [37]. Regarding the combined use of lapatinib and trastuzumab, clinical studies hinted at the effectiveness of the small molecule against brain metastases [38]. Lapatinib proved to be efficient in breast cancer refractory to trastuzumab and seems to cross the blood-brain barrier [39, 40].

The example of colorectal cancers and K-ras show the importance of identifying the right target. Recent results hinted at particular K-ras mutations seeming to make anti-EGFR therapy useless, at least in certain colorectal cancers [41, 42]. Cetuximab is less effective in K-ras mutant cancer cells. In parallel, testing of PTEN deficiency might become mandatory for the treatment decision of breast cancer, since trastuzumab is not effective in PTEN-deficient tumours.

Not only the development of new effective substances that are well tolerated is important, it is also necessary to make sure that tumour markers are characterised, the mechanisms of tumour development are understood and that drugs aim at the right targets. 


\section{References}

1 Alitalo KK: Vascular endothelial growth factors.

2 Senger DR, Galli SJ, Dvorak AM, Perruzzi CA, Harvey VS, Dvorak HF: Tumor cells secrete a vascular permeability factor that promotes accumulation of ascites fluid. Science 1983;19:983-985.

3 Risau W: Mechanisms of angiogenesis. Nature 1997; 386:671-674.

4 Dvorak HF: Vascular permeability factor/vascular endothelial growth factor: a critical cytokine in tumor angiogeneseis and a potential target for diagnosis and therapy. J Clin Oncol 2002;20: 4368-4380.

5 Folkman J: What is the evidence that tumors are angiogenesis dependent? J Natl Cancer Inst 1990; 82:4-6.

6 Gasparini G: Angiogenesis in breast cancer. Role in biology, tumor progression, and prognosis. In Bowcock A (ed): Breast Cancer: Molecular Genetics, Pathogenesis, and Therapeutics. Totowa, Humana Press Inc., 1999, pp 347-371.

7 Cobleigh MA, Langmuir VK, Sledge GW, Miller KD, Haney L, Novotny WF, Reimann JD, Vassel A: A phase I/II dose-escalation trial of bevacizumab in previously treated metastatic breast cancer. Semin Oncol 2003;30(suppl 16):117-124.

8 http://clinicaltrials.gov/ct2/show/NCT00119262? term $=e 2104$ and rank $=1$

9 Bergsland EK: Vascular endothelial growth factor as therapeutic target in cancer. Am J Health Syst Pharm 2004;61(suppl 5):S4-S11.

10 Bergsland EK: Update on clinical trials targeting vascular endothelial growth factor in cancer. Am J Health Syst Pharm 2004;61(suppl 5):S12-S20.

11 http://clinicaltrials.gov/ct2/show/NCT00544167?intr $=\% 22$ Doxorubicin $\% 22$ and rank $=7$.

12 http://www.gbg-crf.com/jahrestreffen/SOFIA.ppt.

13 Jain RK: Tumor angiogenesis and accessibility: role of vascular endothelial growth factor. Semin Oncol 2002;29(suppl 16):3-9.

14 Schneider BP, Miller KD: Angiogenesis of breast cancer. J Clin Oncol 2005;23:1782-1790.

15 Sledge GW: What is targeted therapy? J Clin Oncol 2005;23:1614-1615.

16 Garrett TP, McKern NM, Lou M, Elleman TC, Adams TE, Lovrecz GO, Kofler M, Jorissen RN, Nice EC, Burgess AW, Ward CW: The crystal structure of a truncated ErbB2 ectodomain reveals an active conformation, poised to interact with other ErbB receptors. Mol Cell 2003;11:495-505.

17 Cho HS, Mason K, Ramyar KX, Stanley AM, Gabelli SB, Denney DW, Leahy DJ: Structure of the extracellular region of HER2 alone and in complex with the Herceptin Fab. Nature 2003;421: 756-760.

18 Slamon DJ, Clark GM, Wong SG, Levin WJ, Ullrich A, McGuire WL: Human breast cancer: correlation of relapse and survival with amplification of the HER-2/neu oncogene. Science 1987;235: $177-182$.
19 Brennan PJ, Kumogai T, Berezov A, Murali R, Greene MI: HER2/neu: mechanisms of dimerisation/oligomerisation. Oncogene 2000;19:6093-6101.

20 Gullick WJ, Srinivasan R: The type I growth factor receptor family: new ligands and their role in breast cancer. Breast Cancer Res Treat 1998;52:43-53.

21 Sliwkowski MX, Lofgren JA, Lewis GD, Hotaling E, Fendly BM, Fox JA: Nonclinical studies addressing the mechanism of action of trastuzumab (Herceptin). Semin Oncol 1999;26(suppl 12):60-70.

22 Sweeney C, Carraway KL: Ligand discrimination by ErbB receptors: differential signalling through phosphorylation site usage. Oncogene 2000;19: 5568-5573.

23 Nahta R, Esteva FJ: Herceptin: mechanisms of action and resistance. Cancer Lett 2006;232:123-138.

24 Franklin MC, Carey KD, Vajdos FF, Leahy DJ, de Vos AM, Sliwkowski MX: Insights into ErbB signaling from the structure of the ErbB2-pertuzumab complex. Cancer Cell 2004;5:317-328.

25 Attard G, Kitzen JJ, de Bono J, Verweij J, Pronk L, Zhi J, Blagden SP, Reade SE, Zugmaier G, de Jonge MJ: A phase Ib study of pertuzumab (P), a recombinant humanized antibody to HER 2 , and docetaxel (D) in patients (pts) with advanced solid tumors. ASCO 2005; abstr 3166.

26 Agus DB, Gordon MS, Taylor C, Natale RB, Karlan B, Mendelsohn DS, Press MF, Allison DE, Sliwkowski MX, Lieberman G, Kelsey SM, Fyfe G: Phase I clinical study of pertuzumab, a novel HER dimerization inhibitor, in patients with advanced cancer. J Clin Oncol 2005;23:2534-2543.

27 Price-Shavi SA, Jepson S, Li P, Arango M, Rudland PS, Yee L, Carraway KL: Rat Muc4 (sialomucin complex) reduces binding of anti-ErbB2 antibodies to tumor cell surfaces, a potential mechanism for herceptin resistance. Int J Cancer 2002;99:783-791.

28 Stephens P, Hunter C, Bignell G, et al: Lung cancer: intragenic ERBB2 kinase mutations in tumours. Nature 2004;431:525-526.

29 Gennari R, Menard S, Fagnoni F, et al: Pilot study of the mechanism of action of preoperative trastuzumab in patients with primary operable breast tumors overexpressing HER2. Clin Cancer Res 2004; 10:5650-5655.

30 Yakes FM, Chinratanalab W, Ritter CA, King W, Seelig S, Arteaga CL: Herceptin-induced inhibition of phospatidylinositol-3 kinase and Akt is required for antibody-mediated effects on p27, cyclin D1, and antitumor action. Cancer Res 2002;62: 4132-4141.

31 Sergina NV, Rausch M, Wang D, Blair J, Hann B, Shokat KM, Moasser MM: Escape from HER-family tyrosine kinase inhibitior therapy by the kinaseinactive HER3. Nature 2007;445:437-441.

32 Nahta R, Hung MC, Esteva MJ: The HER-2 targeting antibodies trastuzumab and pertuzumab synergistically inhibit the survival of breast cancer cells. Cancer Res 2004;64:2343-2346.
3 Nagata Y, Lan KH, Zhou X, et al: PTEN activation contributes to tumor inhibition by trastuzumab and loss of PTEN predicts trastuzumab resistance in patients. Cancer Cell 2004;6:117-127.

34 Lu YH, Zi X, Zhao Y, Mascarenhas D, Pollak M: Insulin-like growth factor-1 receptor signaling and resistance to trastuzumab (Herceptin). J Natl Cancer Inst 2001;93:1852-1857.

35 Nahta R, Yuan LXH, Zhang B, Kobayashi R, Esteva FJ: Insulin-like growth-factor I receptor/human epidermal growth factor receptor 2 heterodimerization contributes to trastuzumab resistance of breast cancer cells. Cancer Res 2005;65:11118-11128.

36 Untch M, Jackisch C: Therapy with lapatinib: Current status in women with advanced breast cancer. Breast Care 2007;2:76-80.

37 Bendell JC, Domchek SM, Burstein HJ, Harris L, Younger J, Kuter I, Bunnell C, Rue M, Gelman $\mathrm{R}$, Winer E: Central nervous system metastases in women who receive trastuzumab-based therapy for metastatic breast carcinoma. Cancer 2003;97: 2972-2977.

38 Geyer CE, Forster J, Lindquist D, Chan S, Romieu CG, Pienkowski T, Jagiello-Gruszfeld A, Crown J, Chan A, Kaufman B, Skarlos D, Campone M, Davidson N, Berger M, Oliva C, Rubin SD, Stein S, Cameron D: Lapatinib plus capecitabine for HER2-positive advanced breast cancer. N Engl J Med 2006;355:2733-2743.

39 Burris HA, Hurwitz HI, Dees EC, Dowlati A, Blackwell KL, O`Neil B, Marcom PK, Ellis MJ, Overmoyer B, Jones SF, Harris JL, Smith DA, Koch KM, Stead A, Mangum S, Spector N: Phase I safety, pharmacokinetics, and clinical activity study of lapatinib (GW572016), a reversible dual inhibitor of epidermal growth factor receptor tyrosine kinases, in heavily pretreated patients with metastatic carcinomas. J Clin Oncol 2005;23:5305-5313.

40 Lin NU, Carey LA, Liu MC, et al: Phase II trial of lapatinib for brain metastases in patients with HER2+ breast cancer. ASCO Annual Meeting Proceedings 2006;24:abstr 503.

41 Benvenuti S, Sartore-Bianchi A, Di Nicolantonio F, Zanon C, Moroni M, Veronese S, Siena S, Bardelli A: Oncogenic activation of the RAS/RAF signaling pathway impairs the response of metastatic colorectal cancers to anti-epidermal growth factor receptor antibody therapies. Cancer Res 2007;67: 2643-2648.

42 De Rook W, Piessevaux H, De Schutter J, Janssens M, De Hertogh G, Personeni N, Biesmans B, Van Laethem J-L, Peeters M, Humblet Y, Van Custem E, Tejpar S: KRAS wild-type state predicts survival and is associated to early radiological response in metastatic colorectal cancer treated with cetuximab. Ann Oncol 2008;19:508-515. 